\title{
Seismic vulnerability assessment of urban buildings using the rough set theory and weighted linear combination
}

\author{
Yasaman ASADI iDhttps://orcid.org/oooo-0oo2-2890-8972; e-mail: yasaman.asadi7174@gmail.com

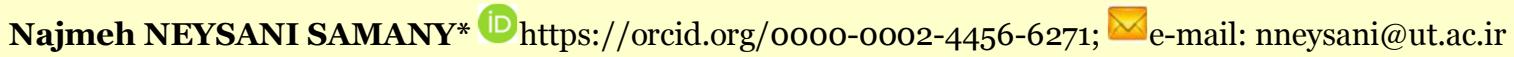 \\ Majid KIAVARZ MOQADAM ID https://orcid.org/oooo-ooo3-0335-3795; e-mail: kiavarzmajid@ut.ac.ir \\ Ata ABDOLLAHI KAKROODI iDhttps://orcid.org/oooo-ooo2-2369-7459; e-mail: a.a.kakroodi@ut.ac.ir
}

Meysam ARGANY ${ }^{i}$ https://orcid.org/oooo-0oo1-6577-4443; e-mail: argany@ut.ac.ir

\author{
${ }^{*}$ Corresponding author
}

Department of Remote Sensing and GIS, Faculty of Geography, University Tehran, Tehran 33137-67464, Iran

Citation: Asadi Y, Neysani Samany N, Kiavarz Moqadam M, et al. (2022) Seismic vulnerability assessment of urban buildings using the rough set theory and weighted linear combination. Journal of Mountain Science 19(3). https://doi.org/10.1007/s11629-021-6724-4

(c) Science Press, Institute of Mountain Hazards and Environment, CAS and Springer-Verlag GmbH Germany, part of Springer Nature 2022

\begin{abstract}
Seismic vulnerability assessment of urban buildings is among the most crucial procedures to post-disaster response and recovery of infrastructure systems. The present study proceeds to estimate the seismic vulnerability of urban buildings and proposes a new framework training on the two objectives. First, a comprehensive interpretation of the effective parameters of this phenomenon including physical and human factors is done. Second, the Rough Set theory is used to reduce the integration uncertainties, as there are numerous quantitative and qualitative data. Both objectives were conducted on seven distinct earthquake scenarios with different intensities based on distance from the fault line and the epicenter. The proposed method was implemented by measuring seismic vulnerability for the seven specified seismic scenarios. The final results indicated that among the entire studied buildings, $71.5 \%$ were highly vulnerable as concerning the highest earthquake scenario (intensity $=7 \mathrm{MM}$ and acceleration calculated based on the epicenter), while in the lowest earthquake scenario (intensity $=5 \mathrm{MM}$ ),
\end{abstract}

Received: $20-\mathrm{Feb}-2021$

Revised: 20-May-2021

Accepted: 05-Sept-2021 the percentage of vulnerable buildings decreased to approximately $57 \%$. Also, the findings proved that the distance from the fault line rather than the earthquake center (epicenter) has a significant effect on the seismic vulnerability of urban buildings. The model was evaluated by comparing the results with the weighted linear combination (WLC) method. The accuracy of the proposed model was substantiated according to evaluation reports. Vulnerability assessment based on the distance from the epicenter and its comparison with the distance from the fault shows significant reliable results.

Keywords: Seismic vulnerability; Urban buildings; Rough set theory; Earthquake scenarios; WLC

\section{Introduction}

Earthquake is one of the natural disasters that causes severe physical, social and financial damages around the world every year Seismic vulnerability assessment is used to determine the likely effects of the hazards on human beings and property within a 
particular area (Delavar and sadrykia 2020), Earthquakes are natural events that can also have long-term social and economic adverse impacts on societies. The vulnerability of cities and settlement areas to natural disasters such as earthquakes is to some extent a consequence of the role of human behaviors and is strongly related to the importance of planning systems in reducing the damaging effects of natural disasters (Yariyan et al. 2020) Tehran, as the capital of Iran and the spiritual hub of the country, is highly susceptible to perils placed forth as the result of an earthquake. This is owed to the fact that Tehran is abundant with faults such as Ray, North of Tehran, Masha, and Kahrizak (Alinia and Delavar 2011; Delavar et al. 2017) fault lines. This highlights the significance of seismic vulnerability assessment approaches, which consider all effective factors (physical and human) and provides grounds for the proposal of flexible models able to handle the inherent uncertainties in both qualitative and quantitative data. By this token, the present study aims to assess the seismic vulnerability of urban buildings, given the effect of both physical and human factors, under different earthquake scenarios.

Recent decades have encountered an increasing number of seismic vulnerability assessment models put forth by different researchers based on GIS-based models (Neysani 2009; Neysani Samany et al. 2014; Nadizadeh Shorabeh et al. 2020; Boloorani et al. 2021; Omidipoor et al. 2021; Jelokhani-Niaraki et al. 2020; Naghdizadegan Jahromi et al. 2021; Boloorani et al. 2021; Qureshi et al. 2021; Neisany Samany et al. 2021). Neves et al. (2012) developed a GIS-based model to measure the seismic vulnerability of urban buildings. They considered building damage and population vulnerability factors and integrated them via a spatial model (Karimzadeh et al. 2014). Delavar et al. (2017) proposed an improved GIS-oriented approach for the assessment of the seismic vulnerability of buildings as well as to estimate the human mortality rate for earthquake scenarios in Tabriz using WLC. Alam and Haque (2018) investigated the seismic vulnerability of urban buildings using intermediate mathematics and grain calculations. Boukri et al. (2018) assessed urban physical seismic vulnerability using a combination of AHP (analytical hierarchical process) and TOPSIS (technique for order preference by similarity to ideal solution) models. Mazumder and Salman (2019) proposed an integrated framework for a seismic damage assessment at an urban scale in Algeria via RADIUS (risk assessment tools for diagnosis of urban areas against seismic disaster) Model. They estimated the expected number of injured individuals and their spatial distributions. Asadi et al. (2019) attempted to assess seismic damage of structures and infrastructure using RADIUS and GIS. Samanta and Swain (2019) applied a fuzzy ordered weighted average (F-OWA) for the assessment of the seismic vulnerability of urban buildings. They concluded that spatial models capable of modeling uncertainty tend to produce more optimized results. Also, they employed nonlinear time series analysis to investigate the interaction of soil structure with urban damages in earthquake disasters. Desalegn and Mulu (2020) applied AHP to weigh and integrate the effective parameters on collapsing buildings. They conducted that the accuracy of experts' knowledge is very sensitive for modeling the vulnerability of buildings. Marasco et al. (2021) developed a new index for buildings' seismic vulnerability. They analyzed the role of each parameter and demonstrated their importance.

A thorough investigation of the literature reveals the following three challenges as the prime obstacles to seismic vulnerability assessment: 1 ) virtually none of the previous methods took into consideration all of the effective factors, where some researches concentrated only on physical factors, others focused on human-directed factors while only partially looking at physical factors. Underground factors were, in particular, missed in the greater number of researches. Therefore, the first contribution of this paper is a comprehensive definition of all effective factors on vulnerability assessment of urban buildings including physical (structural and underground) and human factors. Concerning underground features; the 'underground water depth' parameter is among the most notable factors which could very well lead to soil liquefaction (Alinia and Delavar 2011). The bulk of Tehran's soils consists of alluvial and sandy compositions (Shih 2017). Due to the absence of sewage channels and fairly high water levels especially in the southern parts of the study area, as well as loose layers, sand, and water saturation, buildings will eventually collapse even if not damaged by horizontal forces of the earthquake (Alinia and Delavar 2011). 2) The majority of researches considered only one earthquake scenario per fault line. Accordingly, the second contribution of this paper is the introduction 
of seven distinct earthquake scenarios which take into account both the fault line and the epicenter; and 3) All effective factors and their corresponding integration processes suffer from a certain degree of uncertainty that was habitually ignored in past studies, ergo the employment of rough set theory as the third contribution of this study.

The proposed method was implemented in Districts 11, 16, and 20 of Tehran. A total of seven vulnerability maps were obtained for each earthquake scenario. The experiments were evaluated in two stages: 1) Comparison of vulnerability maps in different scenarios, which demonstrated that considering the distance from the earthquake center as opposed to distance from fault line results in lower vulnerability values, and 2) Comparison of results using the WLC method due to a lack of accurate vulnerability maps of the study area. The final evaluation results confirmed the relatively high accuracy of the proposed method.

\section{Study Area}

The study area encompasses Districts 11, 16, and 20 of Tehran as depicted in Fig. 1. These three areas were selected out of 22 districts in Tehran due to their longitudinal extension, which stretches along a northsouth direction, to obtain an overview of the urban vulnerability of Tehran. In three regions, the average maximum temperature in summer is 42 degrees Celsius and in winter it reaches 4 degrees Celsius and the amount of rainfall is $200 \mathrm{ml}$ per year. Also, the majority of buildings in this area were worn out and dilapidated (especially in district 20) and the underground water level varied between the northern and southern sectors of the studied regions.

\section{Proposed Method}

The problem of determining seismic vulnerability is associated with uncertainty. Rough set theory is the most appropriate method to manage this uncertainty. It was chosen as the most suitable method to discover synthetic rules that exhibit monotonic relationships between composition and process parameters of on seismic vulnerability the one hand, and their final quality on the other hand.

The prime objective of this research is to

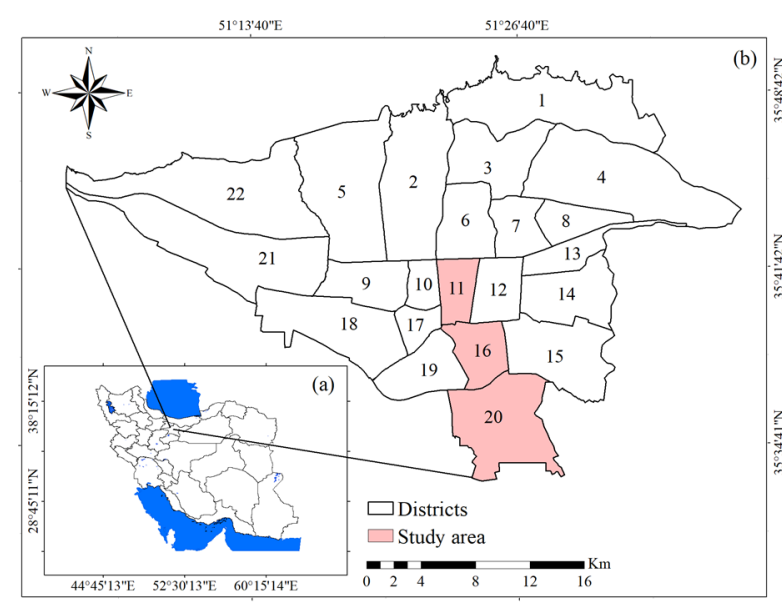

Fig. 1 Study area. (a) Location of Tehran city in Iran and (b) the shape of the 22 districts of Tehran that the study area is three districts 11, 16, and 20 of these 22 districts of Tehran.

Table 1 Earthquake scenarios

\begin{tabular}{|c|c|c|}
\hline Scenario & $\begin{array}{l}\text { Intensity } \\
(\mathrm{MM})\end{array}$ & Description \\
\hline 1 & 5 & Distance from the epicenter \\
\hline 2 & 6 & Distance from the epicenter \\
\hline 3 & 7 & Distance from the epicenter \\
\hline 4 & 6 & $\begin{array}{l}\text { Acceleration due to distance from } \\
\text { fault line }\end{array}$ \\
\hline 5 & 7 & $\begin{array}{l}\text { Acceleration due to distance from } \\
\text { fault line }\end{array}$ \\
\hline 6 & 6 & $\begin{array}{l}\text { Acceleration due to distance from } \\
\text { epicenter }\end{array}$ \\
\hline 7 & 7 & $\begin{array}{l}\text { Acceleration due to distance from } \\
\text { epicenter }\end{array}$ \\
\hline
\end{tabular}

integrate all effective criteria on the seismic vulnerability of urban buildings while accounting for their uncertainty. In this regard, seven earthquake scenarios were defined as listed in Table 1.

As seen all factors are classified into two classes includes physical and human factors. The physical class consists of geotechnical and seismological, structural, and topographic criteria. Each criterion includes a different sub-criterion as depicted in Fig. 2. According to seven earthquake scenarios, rough set theory (as the main approach) and WLC integrate defined factors. Then all mutual maps for each scenario are compared to evaluate the accuracy of the proposed method.

\subsection{Determining the criteria}

An examination of the relative literature (Mouroux et al. 2008; Goda and Hong 2008; Gueguen 2013; Guettiche and Mimoune 2014; 
Sheikhian et al. 2015; Rezaie and Panahi 2015; Karapetrou et al. 2016; Karapetrou et al. 2017; Guettiche et al. 2017; Yariyan et al. 2020; Mesbahi et al. 2020; Delavar and Sadrykia 2020; Yariyan et al. 2021) in conjunction with experts' knowledge revealed two main categories of effective criteria including physical and human factors. The physical category consists of ' 13 ' sub-criteria, while the human category has ' 2 ' subcriteria.

The physical criteria include all the above-ground and underground factors affecting seismic vulnerability. These factors are further classified into three classes as follows:

\subsubsection{Physical criteria}

The first set of physical criteria includes 'Geotechnical and Seismological' factors, which consist of ' 5 ' main sub-criteria explained as so:

(1) Faults Since the occurrences of most earthquakes are caused by active faults, they are among the most crucial factors affecting earthquake vulnerability with a direct impact on damage estimation. To clarify the role of faults in seismic vulnerability assessment, ' 7 ' scenarios were defined, in which the role of faults was investigated from different perspectives. In the first three scenarios, only distance from the epicenter was applied, while the acceleration of each point was calculated using the fault line in scenarios 4 and 5'. Scenarios 6 and 7' were used to measure the acceleration of each point as the result of distance from the epicenter. The acceleration for each point is calculated using Eq. (1) (Esfandiari et al. 2013).

$$
a=\frac{1080 e^{. / 5 M}}{(R+25)^{1 / 32}}
$$

where ' $R$ ' is the distance from the fault line/epicenter in kilometers, $M$ is the magnitude of the earthquake in the Richter scale, $e$ is the constant coefficient equal

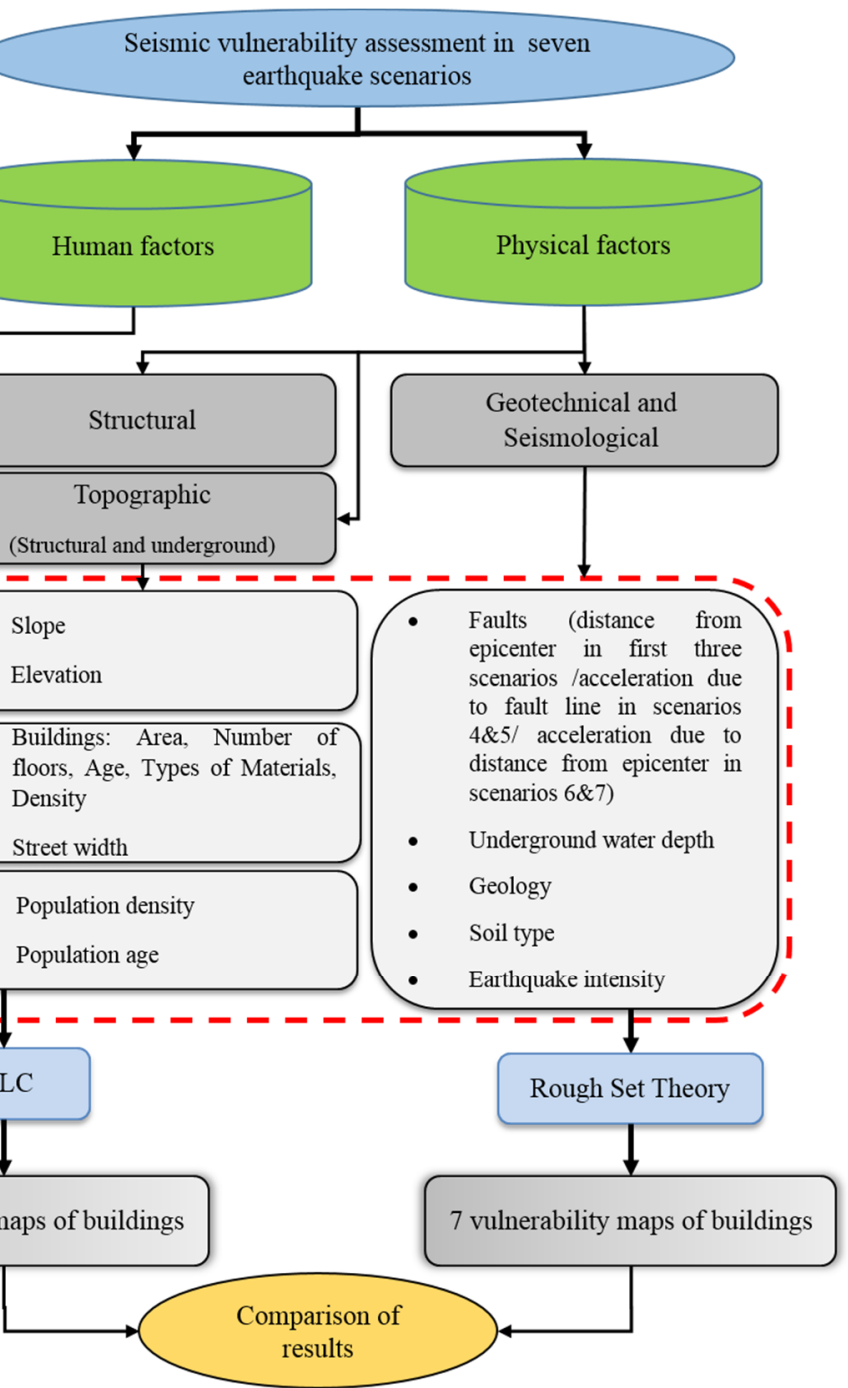

Fig. 2 Flowchart of the proposed method.

to 2.718 , and acceleration is computed in the Gal.

(2) Underground water depth Another salient cause of earthquake failure is the fluidization phenomenon in the soil underlying a structure. By reducing the depth of groundwater, the probability of structural damage to earthquakes increases (Ebrahimi 2015).

(3) Geology Most experts believe that damages to buildings depend, to a large extent, on the construction of the corresponding site for that structure (Khanlari 1996).

(4) Soil type Tehran's soils consist primarily of young alluvial deposits, which are of particular importance in terms of intensification of liquefaction and other earthquake-related phenomena. It has been shown that soft soil environments, especially where the texture of fine and saturated water is damaged, are 5 to 10 times more likely to be adjacent to hard 
rock areas (Rustaie 2007).

(5) Earthquake intensity' The intensity of an earthquake is determined by the impact of earthquakes on humans and facilities. The intensity of the earthquake varies from place to place and decreases as the earthquake focuses. Different measurements have been proposed to determine the intensity of the earthquake. It is commonly assessed on the MMalli scale, due to the advantages it brings to the table concerning observation and measurement of earthquake intensity without the need to install a device (JICA 2000; Silavi 2006). The intensity of an earthquake in a city or a site can be measured using Eq. (2).

$$
I_{R=} I_{0}+6.453-0.00121(R)-4.960 \log (R+20)
$$

where $I_{R}$ is the intensity of earthquakes at the site of the structure on the central scale, $I_{0}$ is the earthquake intensity at the location of the earthquake focal point on the mercalli scale, and $\mathrm{R}$ is the focal length in kilograms.

The second physical criteria set consists of 'Structural' factors, which are categorized into ' 6 ' main sub-criteria as follows:

(6) Building area Vulnerability in smaller parcels commonly results from the shrinking of open space; the larger the space the safer the environment, and by the same token, the smaller the area of a parcel, the more vulnerable it will be.

(7) Number of floors The number of building floors about the width of the passageway and the height of the walls of the buildings is another salient indicator of vulnerability; as the number of building floors increases, the likelihood of the closure of the roads rises due to the high-rise building debris pouring up as well as the disrupting sanitary relief. Also, owing to the relatively large population living in multi-story buildings, evacuation procedures tend to be in such units, and given the large volume of debris, it is much more difficult to save the lives of residents living in high-rise buildings. Therefore, an increase in the number of floors would coincide with increases in the likelihood of vulnerability in such buildings (Qaed Rahmati et al. 2011).

(8) Type of materials The type of structural materials is one of the chiefs and most effective criteria in determining the vulnerability of cities to

${ }^{1}$ The function of the sensation and reception of humans and living organisms from the earthquake, as well as the impact on buildings, is based on the MMI unit, Mercalli. earthquakes. Indubitably, structures built using high standard robust materials improve protection against earthquakes and ensure, to certain degrees, the security of residents.

(9) Building density This factor refers to the percentage of land area used for vertical construction. Higher building density causes a rise in the probability of destruction, and thereby increases vulnerability (Sotoudeh 2000).

(10) Building age This refers to the amount of time passed since the construction of a building. Higher age would promote greater vulnerability.

(11) Street width Street width plays a crucial role in the success of emergency procedures. Wider passageways allow for faster and easier access and relief. More importantly, if one route is blocked or destroyed, other routes can be utilized to reach the desired destination. One other contribution of this factor regards the issue of road traffic and commute in communication networks, especially during peak hours, for which specific precautions must be taken into account (Hosseini 2011).

The third set of physical criteria includes 'Geographical factors, which are comprised of ' 2 ' subcriteria as described below:

(12) Slope The slope is particularly salient in terms of the instability of steep slopes and sand soil, especially under a structure's foundation, in the event of an earthquake (Sarvar 2011) and could lead to heavy destruction and damages.

(13) Elevation Increases in elevation are accompanied by rises in the slope, which in turn increases urban building vulnerability.

\subsubsection{Human criteria}

The human criteria consist of two sub-criteria as follows:

(1) Population density is an indicator of determining the population burden in the event of an earthquake. Larger population densities cause a significant drop in the speed of refuge and relief services.

(2) Population age in light of the vulnerability of people during an earthquake, the age structure of the population, counting on children and the elderly, emerges much more boldly. Put differently, populations below the age of 14 and over the age of 65 are more vulnerable to earthquakes due to certain incapacities. 


\subsection{Integration of criteria using Rough Set theory (RST)}

Rough set theory was put forth by Pawlak (1982) as a mathematical framework for approximate reasoning that considers uncertainty and vagueness in decision-making processes. The idea of rough set theory is based on the premise that knowledge can be classified. Every living being operating in the environment behaves in such a way that real or abstract objects (e.g. things or signals received by the senses) surrounding it could be classified in different ways (Rutkowski 2008) An information system can be expressed as a 4-tuple $\mathrm{S}=\langle\mathrm{U}, \mathrm{A}, \mathrm{V}, \mathrm{f}\rangle$, where $\mathrm{U}$ is a finite set of objects, called the universal set, $\mathrm{A}$ is a finite set of attributes, $\mathrm{V}=\mathrm{U}_{\mathrm{a}} \in \mathrm{AV}_{\mathrm{a}}, \mathrm{V}_{\mathrm{a}}$ being a domain of the attribute a, and $\mathrm{f}: \mathrm{U} \times \mathrm{A} \rightarrow \mathrm{V}$ is called an information function such that $\mathrm{f}(\mathrm{x}, \mathrm{a}) \in \mathrm{V}_{\mathrm{a}}$ for $\forall_{\mathrm{a}} \in$ $\mathrm{A}, \forall \mathrm{x} \in \mathrm{U}$. For every subset $\mathrm{R} \subseteq \mathrm{A}$, an indiscernibility relation on $\mathrm{U}$ is generated as shown in Eq. (3).

$$
\operatorname{IND}(\mathrm{R})=\{(\mathrm{x}, \mathrm{y}) \in \mathrm{U} \times \mathrm{U}: \forall \mathrm{a} \in \mathrm{R}, \mathrm{a}(\mathrm{x})=\mathrm{a}(\mathrm{y})\}
$$

where a (x) is the attribute value of an object $\mathrm{x}$. if $(\mathrm{x}, \mathrm{y})$ $\in \mathrm{IND}(\mathrm{R}), \mathrm{x}$ and $\mathrm{y}$ are said to be indiscernible concerning $\mathrm{R}$, so $\mathrm{x}$ and $\mathrm{y}$ are not distinguishable by $\mathrm{R}$ attributes. The equivalence classes of the undistinguishable $\mathrm{R}$ relation are denoted by $[\mathrm{x}]_{\mathrm{R}}$. Fig 3 illustrates the lower and upper bounds. The lower bound of $\mathrm{X}$ is the set of objects of $\mathrm{U}$ that are surely in $\mathrm{X}$, defined as Eq. (4).

$$
\underline{\mathrm{R}}(\mathrm{X})=\left\{\mathrm{x} \in \mathrm{U}:[\mathrm{x}]_{\mathrm{R}} \subseteq \mathrm{X}\right\}
$$

The upper bound on $\mathrm{X}$ is the set of objects of $\mathrm{U}$ that are possibly in X, is defined as Eq. (5):

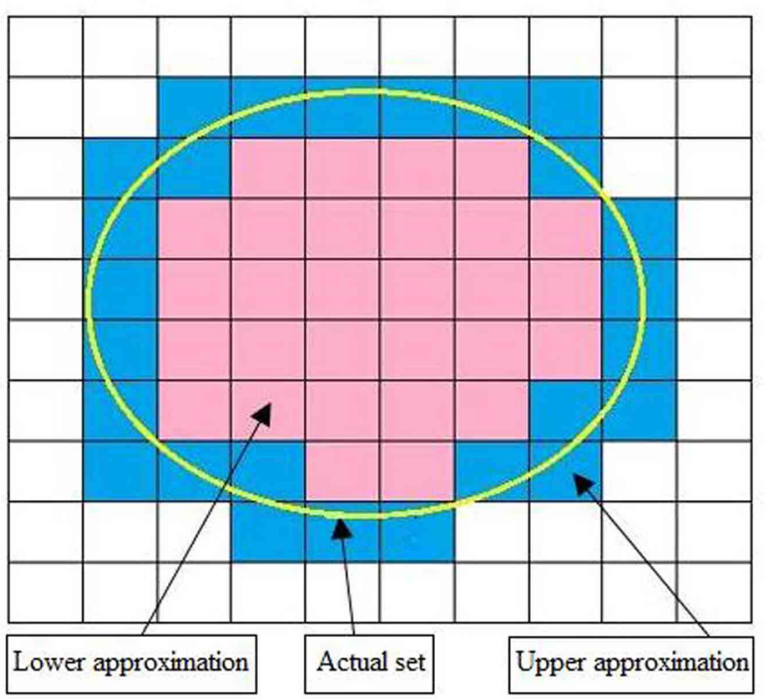

Fig. 3 Lower and upper approximations of a set in RS theory.

$$
\overline{\mathrm{R}}(\mathrm{X})=\left\{\mathrm{x} \in \mathrm{U}:[\mathrm{x}]_{\mathrm{R}} \cap \mathrm{X} \neq \emptyset\right\}
$$

The boundary region of $\mathrm{X}$ is defined as Eq. (6).

$$
\operatorname{Bnd}(\mathrm{X})=\overline{\mathrm{R}}(\mathrm{X})-\underline{\mathrm{R}}(\mathrm{X})
$$

A set is said to be rough if its boundary region is non-empty, otherwise, the set is crisp. Reduct and core attribute sets are two fundamental concepts of RST. A reduct attribute set is a minimal set of attributes from A, provided that the object classification is the same as with the full set of attributes. Given $\mathrm{D}$ and $\mathrm{E} \subseteq \mathrm{A}$, a reduct is a minimal set of attributes such that $\operatorname{IND}(\mathrm{D})=\operatorname{IND}(\mathrm{E})$. Let RED(A) denote all reducts of A. The intersection of all reducts of $\mathrm{A}$ is referred to as a core of $\mathrm{A}$, i.e. CORE(A) $=\cap \operatorname{RED}(\mathrm{A})$, and the core is common to all reducts. Unlike the likelihood of a statistic or membership degree in the fuzzy set theory, this theory is based on the original data and does not require any external information. The RST is not only a suitable tool for analyzing quantitative characteristics, but also for qualitative attributes. This theory explores the salient and relevant features in the data, and explains the rules of decision in the natural language; the decision rule set extracted by the RST eliminates additional data that does not contain specific information.

The weighted linear composition method is a form of multi-criteria evaluation analysis, based on the concept of weighted average. Through this method, analysts or decision-makers assign weights to different criteria based on the relative importance of each criterion examined. Then, by multiplying the relative weight with the value of the corresponding attribute, a final value is obtained for each option. After the final value of each option is determined, options with the highest value are selected for further voting to determine the most suitable option for the target. The value of each option is calculated using Eq. (7).

$\mathrm{WLC}=\left[\left(G_{X 1 \times} W_{S}\right)+\left(G_{X 2} \times W_{S}\right)+\left(G_{X m} \times W_{S}\right)\right]$

As evident, the WLC method starts by assigning initial weights to different criteria. For this purpose, the present study employed the AHP method for pairwise comparison of indices, as a result of which the complexity of the analysis was reduced using a pairwise comparison matrix. AHP calculates the weight of each index with an Eigen-vector corresponding to the highest matrix value and then sums up the components for normal uniformity. In this case, the numerical output was between ' 0 ' and ' 1 '. To obtain the weight of the parameters, ' 25 ' experts in the field of civil engineering, seismology, urban 
planning and, geology were asked to determine the priority of the criteria affecting vulnerability, upon which the AHP method was applied to obtain the final weights for each criterion. AHP was also employed in the weight linear composition method.

\section{Implementation and Results}

To implement the proposed method, a Corei7 Intel processor with RAM8, CPU 1600, and an HD display was used. The proposed method was implemented in 4 steps as follow:

\subsection{Data preparation}

According to the specified criteria in section 3.1, '17' maps were generated in ArcGIS 9.3. All building data were on a scale of 1: 2000. Elevation and slope were derived from SRTM with a resolution of 30 meters. 5700 sample underground water coordinates were used on a scale of 1: 20,000. Soil genus and geological map of Tehran were procured on a scale of 1: 25000, containing 5700 points. All Human-related data were procured at a scale of 1:2000, and then converted into 'UTM Projection -Zone 39 - WGS84) format.

Table 2 shows the classifications of geotechnical and seismological criteria, with corresponding maps shown in (Figs. 4(a,b,c,d,e,f)). The building criteria were classified as shown in (Table 3). (Fig. 4(h,g)) shows certain maps obtained using Street width and Building density. The maps of topographic criteria were classified as listed in Table 4 and were prepared as shown in (Fig. $4(\mathrm{i}, \mathrm{j})$ ). Table 5 lists the humanbased criteria used to obtain zoning maps shown in Figs. 4((k,l))

\subsection{Results of employing RST to integrate criteria and definition of rules}

A total of ' 25 ' rules were extracted to integrate all factors. Some of these rules are denoted in Table 6.

In 'scenario1', the greatest impact on urban vulnerability was observed for underground water depth, followed by population density as the secondhighest impact factor (Fig. 5 (a)).

In 'scenario 2', District 6 shows the highest vulnerability among other regions in the study area. This is due to its proximity to the earthquake center, low underground water depth as well as relatively
Table 2 Geotechnical and seismological criteria and classes

\begin{tabular}{|c|c|c|}
\hline $\begin{array}{l}\text { Vulnerability factors } \\
\text { and criteria }\end{array}$ & $\begin{array}{l}\text { Vulnerability } \\
\text { class }\end{array}$ & $\begin{array}{l}\text { Interval } \\
\text { values }\end{array}$ \\
\hline \multirow{5}{*}{$\begin{array}{l}\text { Distance from the } \\
\text { earthquake center (m) }\end{array}$} & 5 & $9694-7176$ \\
\hline & 4 & $7175-4586$ \\
\hline & 3 & $3054-4885$ \\
\hline & 2 & $3053-1413$ \\
\hline & 1 & $0-1412$ \\
\hline \multirow{5}{*}{$\begin{array}{l}\text { Underground } \\
\text { water depth (m) }\end{array}$} & 5 & $11-19$ \\
\hline & 4 & $20-30$ \\
\hline & 3 & $31-46$ \\
\hline & 2 & $47-62$ \\
\hline & 1 & $63-85$ \\
\hline \multirow{4}{*}{ Geology } & 4 & River Alluvium \\
\hline & 3 & Old river Alluvium \\
\hline & 2 & Mass lime \\
\hline & 1 & Gray lime dark \\
\hline \multirow{7}{*}{ Soil type } & 7 & Clay \\
\hline & 6 & Clay wales \\
\hline & 5 & Clay sand \\
\hline & 4 & Dense gravel-clay \\
\hline & 3 & Sandy \\
\hline & 2 & Gravel \\
\hline & 1 & Rock \\
\hline \multirow{3}{*}{$\begin{array}{l}\text { Earthquake intensity } \\
(\mathrm{MM})\end{array}$} & 3 & 7 \\
\hline & 2 & 6 \\
\hline & 1 & 5 \\
\hline
\end{tabular}

high construction density, and low width of streets. These factors had the highest contribution to heavy building damages in other districts (Fig. 5 (b)). The lowest level of vulnerability was observed in the northern sectors of District 11. A glance at the criteria maps, reveals that the most salient factor for vulnerability reduction in Region 11 was Underground water depth. District 11 had the highest depth and consisted of mostly dense sand soil - clay and a geological position on the alluvial foothills of the old rivers. Further assessment of the vulnerability map in 'scenario 2' indicates that only $37.6 \%$ of the study area is in a very low (12.6\%) and low (25\%) level of vulnerability, while the majority of the study area was in moderate to a very high level of vulnerability.

According to results for 'scenario 3', all three districts of the study area were labeled as relatively high vulnerability (41.4\% of the region was in the high and very high vulnerability range). The highest level of vulnerability was in District 16, most likely the result of its proximity to the earthquake epicenter, low underground water depth, and relatively high building density. Moreover, the southern parts of District 11 and southwest of District 20 were classified as very vulnerable. The least damage was seen towards the northern parts of District 11, which as an 

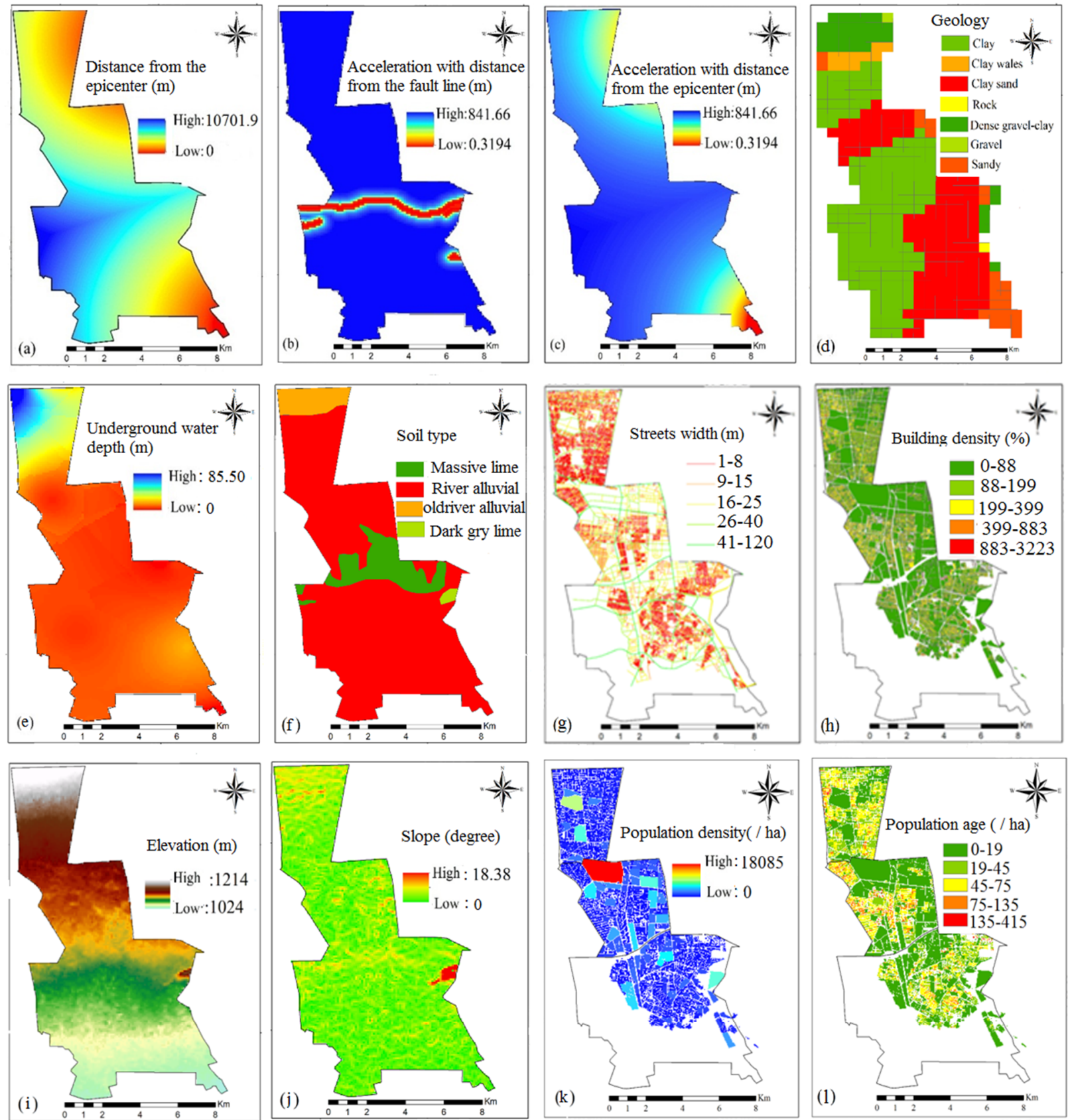

Fig. 4 Maps of geotechnical and seismological criteria a) Distance from the focal point (m), distance from epicenter in first three scenarios(m), b) Acceleration map obtained using the distance from fault line for scenarios 4 \& 5 (g), c) Acceleration map obtained using the distance from epicenter for scenarios 6 \& 7 (g), d) Geology, e) Underground water depth (m), f) Soil type, g) Streets width(m), h) Building density (\%), i) Elevation (m), j) Slope (degree), k) Population density, l) Population age.

examination of the standard maps show, is due to the soil, geology, and the high underground water depth as well as its remoteness to the earthquake epicenter.

Acceleration rates were calculated for each point in 'scenario 4' to 'scenario 7' (Fig. 5 (d) and (g)). As evident, there is a significant difference between the vulnerability maps in scenarios (1-3) and (4-7). As one of the objectives of this study is to compare the effects of considering 'distance from fault line' and 'distance from earthquake center' under similar intensity conditions, the seismic vulnerability maps of scenarios 4, 6, and 5, 7 are shown separately in Fig. 5 . Inter comparisons between vulnerability maps of scenarios 4 and 6 indicate that the larger part of the 
study area (61\% in scenario 4 and $52 \%$ in scenario 6 ) is in a very high and high class of vulnerability, while in scenario 4, proximity to the fault line is the prime contributor to damages. The moderate and high vulnerability classes (Delavar \& Sadrykia 2020; Yariyan et al. 2020; Asadi et al. 2019) have the highest share among their counterparts, with similar vulnerabilities also observed in both scenarios.

The comparison between vulnerability maps of scenarios 5 and 7 reveals that the majority of the study area ( $72 \%$ in scenario 5 and $68 \%$ in scenario 7$)$ falls within the very high and high classes of vulnerability, wherein proximity to the fault line was shown to have the most significant effect on the incidence of damages in scenario 5. However, the moderate and high vulnerability classes claim the highest percentages in the area, with similar vulnerabilities also evident in both scenarios. Moreover, a comparison between Figs. 5 ((d), (e) and (f), (g)) specify that the increase of earthquake intensity from 6 to 7 MMalli, will most probably lead to significantly heavier damages in the study area.

\subsection{Criteria Weighting and WLC}

The weighted linear composition method is perhaps the most frequently used technique in multicriteria analysis. In this study, WLC was used to aggregate the different criteria based on their weights, which in turn were determined according to their relevance and impact on seismic vulnerability. The

Table 4 Topographic classes and rates

\begin{tabular}{|l|l|l|}
$\begin{array}{l}\text { Vulnerability factors } \\
\text { and criteria }\end{array}$ & $\begin{array}{l}\text { Vulnerability } \\
\text { class }\end{array}$ & $\begin{array}{l}\text { Class } \\
\text { boundary }\end{array}$ \\
\hline \multirow{3}{*}{ Slope (degree) } & 1 & $0-0.72$ \\
& 2 & $0.73-1.51$ \\
\hline & 3 & $1.52-4-39$ \\
\hline Elevation (m) & 4 & $4.4-10.23$ \\
& 5 & $10.24-18.38$ \\
\hline & 1 & $1024-1056$ \\
\hline & 3 & $1057-1085$ \\
\hline & 4 & $1086-1120$ \\
\hline & 5 & $1121-1161$ \\
\hline
\end{tabular}

Table 3 Building criteria, classes, and rates

\begin{tabular}{|c|c|c|}
\hline $\begin{array}{l}\text { Vulnerability factors } \\
\text { and criteria }\end{array}$ & $\begin{array}{l}\text { Vulnerability } \\
\text { class }\end{array}$ & Class boundary \\
\hline \multirow{9}{*}{$\begin{array}{l}\text { Area } \\
\left(\mathrm{m}^{2}\right)\end{array}$} & 9 & $>500$ \\
\hline & 8 & $300-500$ \\
\hline & 7 & $200-300$ \\
\hline & 6 & $150-200$ \\
\hline & 5 & $100-150$ \\
\hline & 4 & $80-100$ \\
\hline & 3 & $75-80$ \\
\hline & 2 & $50-75$ \\
\hline & 1 & $<50$ \\
\hline \multirow{5}{*}{$\begin{array}{l}\text { Street width } \\
\text { (m) }\end{array}$} & 5 & $1-8$ \\
\hline & 4 & $9-15$ \\
\hline & 3 & $16-25$ \\
\hline & 2 & $26-40$ \\
\hline & 1 & $41-120$ \\
\hline \multirow{5}{*}{ Number of floors } & 5 & $<16$ \\
\hline & 4 & $11-15$ \\
\hline & 3 & $6-10$ \\
\hline & 2 & $3-5$ \\
\hline & 1 & $<3$ \\
\hline \multirow{4}{*}{$\begin{array}{l}\text { Building age } \\
\text { (years) }\end{array}$} & 4 & $>25$ \\
\hline & 3 & $16-25$ \\
\hline & 2 & $5-15$ \\
\hline & 1 & $<5$ \\
\hline \multirow{5}{*}{ Type of materials } & 5 & Others \\
\hline & 4 & cement block \\
\hline & 3 & Iron and steel \\
\hline & 2 & Metal and concrete \\
\hline & 1 & reinforced concrete \\
\hline \multirow{5}{*}{$\begin{array}{l}\text { Building density } \\
\text { (\%) }\end{array}$} & 5 & $>883$ \\
\hline & 4 & $399-883$ \\
\hline & 3 & $199-399$ \\
\hline & 2 & $88-199$ \\
\hline & 1 & $<88$ \\
\hline
\end{tabular}

Table 5 Human criteria, classes, and rates.

\begin{tabular}{|l|l|l|}
$\begin{array}{l}\text { Vulnerability factors } \\
\text { and criteria }\end{array}$ & $\begin{array}{l}\text { Vulnerability } \\
\text { class }\end{array}$ & $\begin{array}{c}\text { Class } \\
\text { boundary }\end{array}$ \\
\hline $\begin{array}{l}\text { Population density } \\
\text { (/ha) }\end{array}$ & 5 & $>5980$ \\
& 4 & $2487-5980$ \\
& 3 & $949-2487$ \\
& 2 & $228-949$ \\
\hline Population age & 1 & $<228$ \\
(/ha) & 5 & $136-415$ \\
& 4 & $75-136$ \\
& 3 & $45-75$ \\
& 2 & $19-45$ \\
\hline & 1 & $<19$ \\
\hline
\end{tabular}

Table 6 Sample rough set rules for vulnerability assessment

\begin{tabular}{|l|l} 
Rules Linguistic form of defined decision rules \\
$R_{0}$ & IF (geology.1) AND (soil.1) AND (depth of water.1) AND (distance from earthquake.1) THEN (very high vulnerability) \\
$R_{1}$ & IF (geology.o) AND (soil.1) AND (depth of water.1) AND (distance from earthquake.1) THEN ( high vulnerability) \\
$R_{2}$ & IF (geology.o) AND (soil.o) AND (depth of water.1) AND (distance from earthquake.1) THEN (moderate vulnerability) \\
$R_{3}$ & IF (geology.o) AND (soil.o) AND (depth of water.o) AND (distance from earthquake.1) THEN (low vulnerability) \\
$R_{4}$ & IF (geology.o) AND (soil.o) AND (depth of water.o) AND (distance from earthquake.o) THEN (very low vulnerability)
\end{tabular}



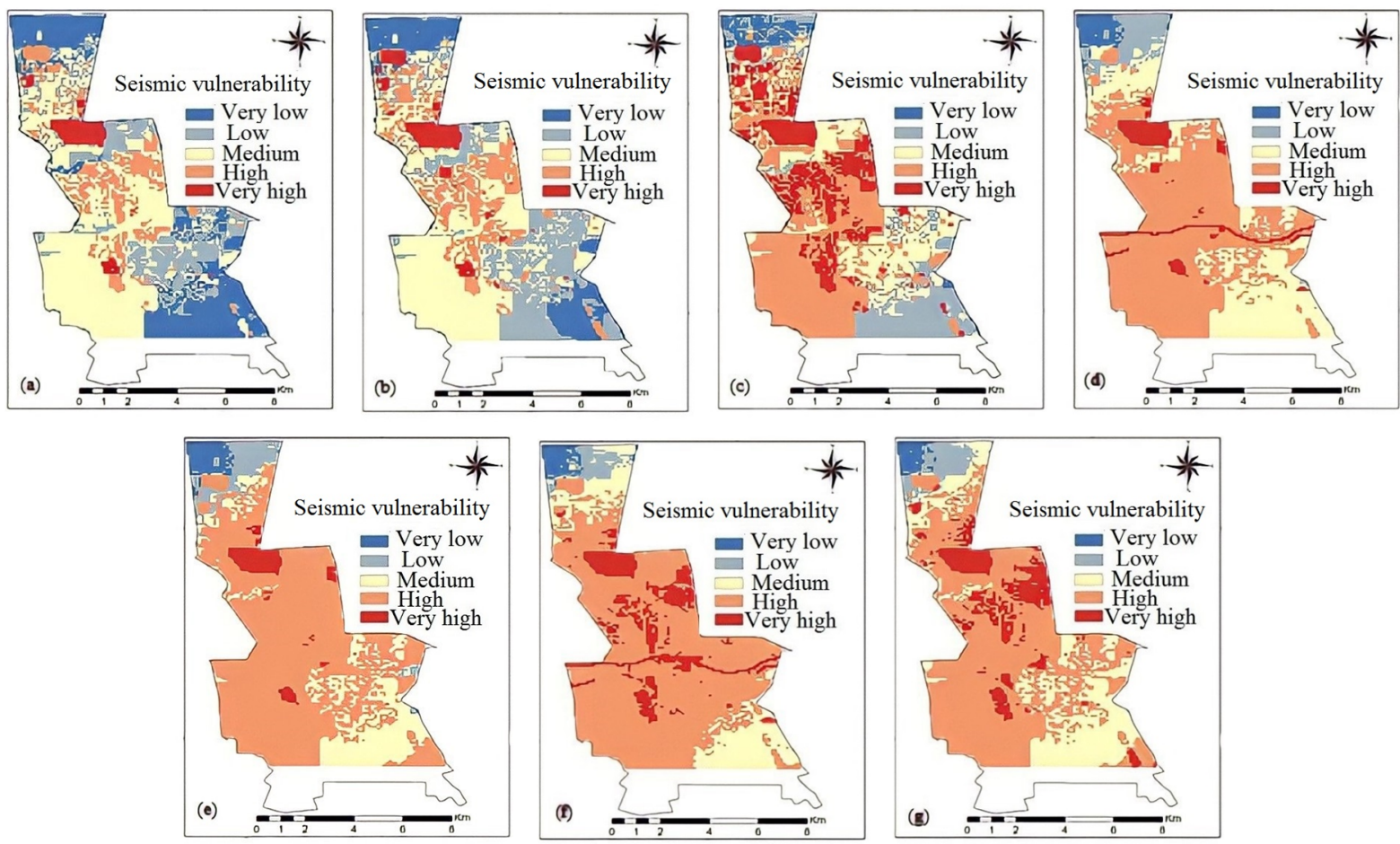

Fig. 5 Seismic vulnerability (Class) maps of buildings obtained using RST in (a) 'scenario 1', b) 'scenario 2', c) 'scenario 3', d) ‘scenario 4', e) ‘scenario 6', f) 'scenario 5', g) 'scenario 7'.

WLC procedure was instigated by initially ranking all the mentioned criteria and sub-criteria in Fig. 2 using AHP. The obtained weights were assigned by 25 experts as described in Table 7.

Afterward, vulnerability maps were generated for each scenario using Eq. (7) (Fig. 6).

\subsection{Comparison of RST and WLC vulnerability maps}

To evaluate the accuracy of the proposed method, the vulnerability maps produced by RST were compared with those obtained using WLC (Figs 5 versus 6). Table 8 display the differences between these two methods for scenarios 1-7 using diagrams of vulnerability percentages for each class. Evaluation results for each scenario are as follows:

(1) Scenario 1 Comparison between RST and WLC seismic vulnerability maps for 'scenario 1' (Figs. 5(a) and 6(a)), are indicative of lower levels of vulnerability in the south and south-east parts of District 20 when using RST. Moreover, the central and southern parts of District 11 and the entire area of District 16 showed higher levels of vulnerability when using RST as opposed to running the WLC method. The results were somewhat similar to other regions. Differences between the percentage of vulnerability
Table 7 Criteria and sub-criteria weights obtained using analytical hierarchical process (AHP)

\begin{tabular}{|l|l|}
\hline Building criteria & Final weight \\
\hline Building material & 0.4332 \\
\hline Building density & 0.2191 \\
\hline Age of building & 0.1121 \\
\hline Streets width & 0.1071 \\
\hline Number of floors & 0.0807 \\
\hline Building area & 0.0478 \\
\hline Inconsistency factor & 0.06 \\
\hline Underground & \\
\hline Distance to earthquake center & 0.7321 \\
\hline Underground water depth & 0.1464 \\
\hline Type of soil & 0.0732 \\
\hline Geology & 0.0483 \\
\hline Inconsistency factor & 0.07 \\
\hline Topographic & \\
\hline Slope & 0.8749 \\
\hline Elevation & 0.1251 \\
\hline Inconsistency factor & 0.04 \\
\hline Human & \\
\hline Population density & 0.7519 \\
\hline Population age & 0.2481 \\
\hline Inconsistency factor & 0.05 \\
\hline
\end{tabular}

areas for scenario 1 using RST and WLC (Table 8) signals a significant discrepancy, especially in the case of moderate and very high vulnerability classes.

(2) Scenario 2 The results were virtually identical in this scenario for both WLC and RST. Nevertheless, WLC vulnerability maps signal an 

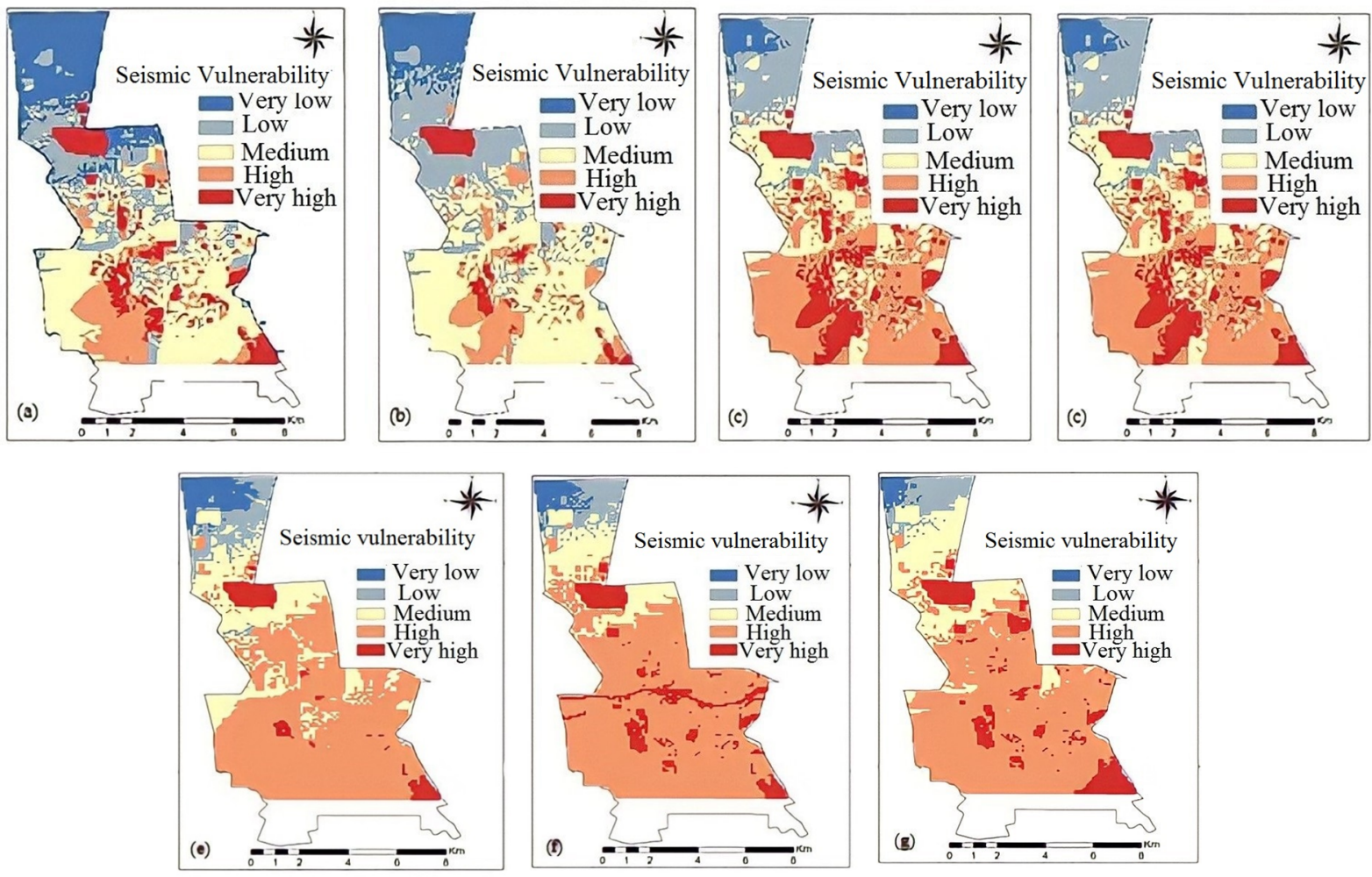

Fig. 6 Seismic vulnerability (Class) maps of buildings obtained using the WLC in (a) 'scenario 1', b) 'scenario 2', c) 'scenario 3', d) ‘scenario 4', e) ‘scenario 6', f) ‘scenario 5', g) ‘scenario 7'.

increase in damages from north to the south of the studied area compared to RST. Furthermore, District 20 was declared more vulnerable among the three districts when applying the WLC method. Comparison of the diagrams in Table 8 shows that the moderate vulnerability class had the highest share of the study region, while the very high vulnerability class had the lowest percentage.

(3) Scenario 3 Both methods produced practically identical results for this scenario.

Comparisons between seismic vulnerability maps for scenarios 1-3 are stipulated of the similarity between both models under increased earthquake intensity.

(4) Scenario 4 Inter-contrasting of diagrams shown in Table 8 indicates that the maps obtained using both methods were more or less the same for both the 'high', and the 'very high' classes. On the other hand, larger percentages of the study area were labeled as 'moderate' vulnerability when using RST, while regarding the 'low', and the 'very low' classes, RST covered lower percentages of the study area as opposed to WLC.

(5) Scenario 5 Evaluation of diagrams depicted in Table 8 indicates that similar regions were classified as 'very low, 'low' and 'very high' vulnerable areas using
Table 8 Comparison of vulnerability assessments for each class obtained using the Rough Set theory (RST) and the Weighted Linear Combination (WLC) methods in Scenarios 1 to 7

\begin{tabular}{|c|c|c|c|c|c|c|}
\hline \multirow{2}{*}{ Methods } & & \multicolumn{5}{|c|}{ Class categories* } \\
\hline & & 1 & 2 & 3 & 4 & 5 \\
\hline \multirow{2}{*}{ Scenario 1} & RST & 21.8 & 20.3 & 41.4 & 12.9 & 3.6 \\
\hline & WLC & 20.8 & 19.4 & 34.6 & 14.5 & 10.7 \\
\hline \multirow{2}{*}{ Scenario 2} & RST & 12.6 & 25 & 40.6 & 16.6 & 5.1 \\
\hline & WLC & 11.2 & 25 & 42.5 & $15 \cdot 4$ & $5 \cdot 9$ \\
\hline \multirow{2}{*}{ Scenario 3} & RST & 3.9 & 16.6 & 21.2 & 40.9 & 17.4 \\
\hline & WLC & $4 \cdot 3$ & $17 \cdot 5$ & 20.3 & 41.4 & 16.5 \\
\hline \multirow{2}{*}{ Scenario 4} & RST & 4 & $7 \cdot 3$ & 19.5 & 65.4 & 3.8 \\
\hline & WLC & 8.7 & 11.1 & 12.7 & 61.1 & 6.3 \\
\hline \multirow{2}{*}{ Scenario 5} & RST & $3 \cdot 9$ & 8.1 & 28.1 & 54 & 5.9 \\
\hline & WLC & $5 \cdot 4$ & $7 \cdot 5$ & 21.8 & 60.4 & 4.9 \\
\hline \multirow{2}{*}{ Scenario 6} & RST & 3.2 & 5.8 & 13 & 66 & 11.1 \\
\hline & WLC & 1.2 & 2.1 & 15 & 71.5 & 10.2 \\
\hline \multirow{2}{*}{ Scenario 7} & RST & 1.9 & 4.6 & 20.4 & 61.6 & 11.5 \\
\hline & WLC & 1.7 & 6 & 18.8 & 62 & 11.5 \\
\hline
\end{tabular}

Note: *Class categories: 1 , very low; 2 , low; 3 , medium; 4, High; 5, very high.

both methods. However, smaller percentages of the study area fell within the 'moderately' vulnerable class when using RST compared to WLC, while areas labeled as 'high' vulnerability contributed to a smaller percentage of the study area when using WLC as contrasted with RST. 
It can be concluded that the use of distance from fault lines and distance from earthquake epicenter generates significantly different seismic vulnerability maps for scenarios 4 and 6 .

(6)Scenario 6 Comparison of diagrams in Table 8 shows similar areas classified as 'very low, 'moderate', and 'very high' for both methods. Nonetheless, according to RST, the 'low' class contributed to a larger share of the area, while the 'high' class covered a lower percentage of the region compared to results from the WLC method.

(7) Scenario 7 Both methods produced similar results for this scenario (Table 8).

Comparisons between seismic vulnerability maps obtained using both methods for scenarios 5 and 7 demonstrate how using the distance from fault lines and earthquake centers will result in significantly different seismic vulnerability maps, albeit the effects tend to attenuate with increases in earthquake acceleration. Moreover, under increased earthquake intensity, both models act similarly.

\section{Conclusions}

This paper aims to contribute to assessing the seismic vulnerability of urban buildings while taking into account uncertainties. For this purpose, seven different earthquake scenarios were initially defined, upon which all involved physical and human criteria were classified into 15 categories. The criteria were then integrated via rough set theory. The proposed method was implemented in Districts 11, 16 and, 20 of Tehran, Iran, considered one of the most vulnerable metropolitans at the hazard of earthquakes.

The findings from different scenarios demonstrated that 1) Districts 16 and 20 in conjunction with southern parts of District 11 are more vulnerable compared to the remaining areas, which is primarily due to the underground water depth in these areas (groundwater level is higher in Districts 20 and 16 compared to the southern parts of District 11) and secondary is due to the proximity of these areas to the focal point, 2) The depth of the underground water level from the north to the south of the study area has decreased, thereby seismic vulnerability in the mentioned areas are increased. Consequently, the vulnerability has significantly increased from north to south, as confirmed by the WLC method, and 3) By comparing earthquake acceleration scenarios at different intensities, the findings also stipulated those zones labeled vulnerable using distance from the earthquake centers are less in percentage as those obtained using distance from fault lines.

\section{Acknowledgments}

The National Cartographic Center and Geological Survey of Iran are most appreciation for data preparation. The authors acknowledge with appreciation their persistent care, so vital to the accomplishment of this research.

\section{References}

Alam MS, Haque SM (2018) Assessment of urban physical seismic vulnerability using the combination of AHP and TOPSIS models: A case study of residential neighborhoods of Mymensingh city, Bangladesh. J Geosci Environ Prot 6(02): 165-183. https://doi.org/10.4236/gep.2018.62011

Alinia HS, Delavar MR (2011) Tehran's seismic vulnerability classification using granular computing approach. Appl Geomat 3(4): 229-240. https://doi.org/10.1007/s12518-011-0068-7

Asadi Y, Samany NN, Ezimand K (2019) Seismic vulnerability assessment of urban buildings and traffic networks using a fuzzy ordered weighted average. J Mt Sci 16(3): 677-688. https://doi.org/10.1007/s11629-017-4802-4

Boloorani AD, Shorabeh SN, Samany NN, et al. (2021) Vulnerability mapping and risk analysis of sand and dust storms in Ahvaz, IRAN. Environ Pollut (279): 116859.

https://doi.org/10.1016/j.envpol.2021.116859.

Boukri M, Farsi MN, Mebarki A, et al. (2018) Seismic vulnerability assessment at urban scale: Case of Algerian buildings. Int $\mathrm{J}$ Disaster Risk Reduct (31):555-575.

https://doi.org/10.1016/j.ijdrr.2018.06.014
Delavar MR, Bahrami M, Zare M (2017) Physical seismic vulnerability assessment of Tehran using the integration of granular computing and interval dempster- Shafer. Int Arch Photogramm Remote Sens Spatial Inf Sci 18-22 https://doi.org/10.5194/isprs-archives-XLII-2-W7-469-2017

Delavar MR, Sadrykia M (2020) Assessment of Enhanced Dempster-Shafer Theory for Uncertainty Modeling in a GISBased Seismic Vulnerability Assessment Model, Case StudyTabriz City. Int J Geo-Inf 9(195).

https://doi.org/10.3390/ijgig040195

Desalegn H, Mulu A (2020) Flood vulnerability assessment using GIS at Fetam watershed upper Abbay basin Ethiopia. Heliyon 7(1) e05865. https://doi.org/ 10.1016/j.heliyon.2020.e05865

Esfandiari F, Ghafari A, Lotfi KH (2013) Modeling the vulnerability of cities to earthquakes using Topsis method GIS environment. J Amst (2):43-79. http://www.geomorphologyjournal.ir/article_ 77909.html?lang=fa

Ebrahimi M, Salmani M, Amir Ahmadi A,Nouri M (2015) Evaluation of seismic vulnerability of Bardaskan city against earthquake using inverted hierarchical model (IHPW). 
Environmental Hazards 6:105-137 https://journals.usb.ac.ir/article_2526.html (Persian)

Goda K, Hong HP (2008). Spatial correlation of peak ground motions and response spectra. Bull Seismol Soc Amer 98(1): 354365. https://doi.org/10.1785/0120070078

Gueguen P (2013) Seismic vulnerability of structures. John Wiley \& Sons. pp 1-368. https://www.wiley.com/en-aw/Seismic+ Vulnerability+of+Structures-p-9781118603925

Guettiche A, Mimoune M (2014) Analysis of seismic vulnerabilitycase of buildings of high seismic hazard. J Mater Res (875):416422.

https://doi.org/10.4028/www.scientific.net/AMR.875-877.416

Guettiche A, Guéguen P, Mimoune M (2017) Seismic vulnerability assessment using association rule learning: application to the city of Constantine, Algeria. Environ Hazard 4 86(3):1223-1245. https://doi.org/10.1007/s11069-016-2739-5

Hosseini A (2011) Passive defense criteria for designing urban collective buildings. Armanshahr Archit \& Urbab Develop (2): 271-282. https://doi.org/10.1007/978-3-540-87395-2_17.

Jelokhani-Niaraki M, Neysani Samany N, Mohammadi $\bar{M}$ (2020) A hybrid ridesharing algorithm based on GIS and ant colony optimization through geosocial networks. J Ambient Intell Hum Comput (12): 2387-2407. https://doi.org/10.1007/s12652-020-02364-6.

JICA (Japan international cooperation agency) (2000) The study on Seismic micro zoning of the greater Tehran area in the Islamic Republic of Iran (Final Report). http://open_jicareport.jica.go.jp

Karapetrou S, Manakou M, Bindi D, et al. (2016) Time-building specific seismic vulnerability assessment of a hospital RC building using field monitoring data. Eng Struct (112): 114-132. https://doi.org/10.1016/j.engstruct.2016.01.009

Karapetrou ST, Fotopoulou SD, Pitilakis KD (2017) Seismic vulnerability of RC buildings under the effect of aging. Procedia Environ Sci (38): 461-468. https://doi.org/10.1016/j.proenv.2017.03.137

Karimzadeh S, Miyajima M, Hassanzadeh R, et al. (2014) A GISbased seismic hazard, building vulnerability and human loss assessment for the earthquake scenario in Tabriz. Soil Dyn Earthq Eng (66): 263-280. https://doi.org/10.1016/j.soildyn.2014.06.026.

Khanlari G (1996) Geological engineering. First Edition. Hamedan, University of Abu Ali Sina. J Eng Geol. https://b2n.ir/z75457

Marasco S, Zamani Noori A, Domaneschi Gian M, et al. (2021) Seismic vulnerability assessment indices for buildings: Proposals, comparisons and methodologies at collapse limit states. Int $\mathrm{J}$ Disaster Risk Reduct (102466). https://doi.org/10.1016/j.ijdrr.2021.102466

Mazumder RK, Salman, A M (2019). Seismic damage assessment using RADIUS and GIS: A case study of Sylhet City, Bangladesh. Int J Disaster Risk Reduct (34):243-254. https://doi.org/10.1016/j.ijdrr.2018.11.023

Mesbahi F, Akbari Baghi M, Nadiri A (2020) Assessment and mapping of the seismic vulnerability of Tabriz city using the Fuzzy logic. J Adv Environ Health Res (8):181-192. https://doi.org/10.22102/jaehr.2020.242457.1179

Mouroux P, Le Brun B (2008) Risk-Ue Project: an advanced approach to earthquake risk scenarios with application to different European towns. Springer. pp 479-508. https://doi.org/10.1007/978-1-4020-3608-8_23

Nadizadeh Shorabeh S, Varnaseri A, Firozjaei MK, et al. (2020). Spatial modeling of areas suitable for public libraries construction by integration of GIS and multi-attribute decision making: Case study Tehran, Iran. Libr Inf Sci Res 42(2) 101017. https://doi.org/10.1016/j.lisr.2020.101017.

Naghdizadegan Jahromi M, Gomeh Z, etal. (2021) Developing a SINTACS-based method to map groundwater multi-pollutant vulnerability using evolutionary algorithms. Environ Sci Pollut Res (28): 7854-7869.

https://doi.org/10.1007/s11356-020-11089-0

Neisany Samany N, Delavar MR, Saeedi S, et al. (2009) 3D continuous K-NN query for a landmark-based wayfinding location-based service. J 3D GIS 271-282.
Neves F, Costa A, Vicente R, et al. (2012) Seismic vulnerability assessment and characterization of the buildings on Faial Island, Azores. Bull Earthq Eng 10(1):27-44.

https://doi.org/10.1007/s10518-011-9276-o

Neysani Samany N (2019) Automatic landmark extraction from geotagged social media photos using deep neural network. Cities (93):1-12. https://doi.org/10.1016/j.cities.2019.04.012.

Neysani Samany N, Toomanian A, Maher A, et al. (2021) The most places at risk surrounding the COVID-19 treatment hospitals in an urban environment- case study: Tehran city. Land Use Policy (109): 1-14. https://doi.org/10.1016/j.landusepol.2021.105725

Neysani Samany N, Delavar MR, Chrisman N, Malek MR (2014) FIA5: a customized Fuzzy Interval Algebra for modeling spatial relevancy in urban context-aware systems. Eng Appl Artif Intell (33):116-126. https://doi.org/10.1016/j.engappai.2014.04.004

Omidipoor M, Toomanian A, Neysani Samany N, Mansourian A (2021) Knowledge Discovery Web Service for Spatial Data Infrastructures. Int J Geo-Inf 10 (1):1- 12.

https://doi.org./10.3390/ijgi10010012.

Yariyan P, Avand M, Soltani F, et al. (2020) Earthquake Vulnerability Mapping Using Different Hybrid Models. Symmetry 12(3): 405. https://doi.org/10.3390/sym12030405

Qaed Rahmati S, Bastanifar A, Soltani L (2011) Investigation of the effects of condensation on earthquake vulnerability in Isfahan (with fuzzy approach) (1): 107-122. https://journals.ui.ac.ir/article_18488.html

Qureshi S, Nadizadeh Shorabeh S, Neysani Samany N (2021) a new integrated approach for municipal landfill siting based on urban physical growth prediction: a case study mashhad metropolis in Iran. Remote Sens 13(5):949-964. https://doi.org/10.3390/rs13050949.

Rezaie F, Panahi M (2015). GIS modeling of seismic vulnerability of residential fabrics considering geotechnical, structural, social, and physical distance indicators in Tehran using multi-criteria decision-making techniques. Nat Hazards Earth Syst Sci 15(3): 461-474. https://doi.org/10.5194/nhess-15-461-2015

Rustaie S (2007) zoning of Tabriz Fault Risk for Different Uses of Urban Land. J Geo- Dev 9(2).

Rutkowski L (2008) Computational intelligence: methods and techniques. J SSBM. https://www.springer.com.book

Samanta A, Swain A (2019) Seismic response and vulnerability assessment of representative low, medium, and high-rise buildings in Patna, India. Structures (19): 110-127. https://doi.org/10.1016/j.istruc.2019.01.002

Sarvar H, Amini J, Laleh-Poor M (2011) Assessment of risk caused by the earthquake in region 1 of Tehran using the combination of RADIUS, TOPSIS, and AHP models. J Civil Eng Urban 1(1): 3948. https://www.ojceu.com

Sheikhian H, Delavar MR, Stein A (2015) Integrated estimation of seismic physical vulnerability of Tehran using rule-based granular computing. Int Arch Photogramm Remote Sens Spatial Inf Sci 40(3):187. https://doi.org/10.5194/isprsarchives-XL-3-W3-187-2015

Shih DCF (2017) Groundwater storage inferred from earthquake activities around East Asia and the West Pacific Ocean. J Hydrol (544): 363-372. https://doi.org/10.1016/j.jhydrol.2016.11.029

Silavi T (2006) Evaluation of Seismic Vulnerability in Tehran City by Using Fuzzy Intuition Models. J MS Tehran University.

Sotoudeh B (2000) Land use planning and correction of roads to secure earthquakes, (Case Study: Garden District Ferdows County Municipality of Tehran). Graduate degree urban planning urban and regional planning Shiraz University.

https://www.sid.ir

Yariyan P, Abbaspour RA, Chehreghan A, et al. (2021) GIS-based seismic vulnerability mapping: a comparison of artificial neural networks hybrid models. Geocarto Int. https://doi.org/10.1080/10106049.2021.1892208

Yariyan P, Zabihi H, Wolf I, et al. (2020) Earthquake risk assessment using an integrated Fuzzy Analytic Hierarchy Process with Artificial Neural Networks based on GIS: A case study of Sanandaj in Iran. Int J Disaster Risk Reduct (101705):1-59. https://doi.org/10.1016/j.ijdrr.2020.101705 